\title{
CON

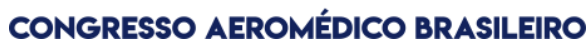

\section{OPERAÇÕES MÉDICAS AÉREAS EM LOCAL MONTANHOSO RESTRITO: EXPERIÊNCIA NA REGIÃO DO SUL DE MINAS GERAIS}

Camila Mendes dos SANTOS ${ }^{1}$;Simone Alessandra Rodrigues Silveira JUNQUEIRA ${ }^{2}$; Márcio Antônio RIOS ${ }^{3}$; João Bosco Lara JÚNIOR ${ }^{4}$

\section{RESUMO}

O Suporte Aéreo Avançado de Vida (SAAV) é uma modalidade de Suporte Avançado de Vida (SAV) presente no Estado de Minas Gerais na realização do transporte e resgate aeromédico. Este estudo tem por objetivo apresentar a atividade desenvolvida durante resgate de vítima em local montanhoso restrito. Trata-se de um relato de experiência vivenciada pelos operadores aerotáticos e de suporte médico da $2^{a}$ Cia do Batalhão de Operações Áereas (BOA) de Minas Gerais. O resgate aeromédico é uma atividade que exige equipe especializada, capacitada e que contemple os preceitos do Crew Resource Management (CRM).

Palavras-chave: Resgate aéreo; Trabalho de Resgate; Gestão de Recursos da Equipe de Assistência à Saúde.

\section{INTRODUÇÃO}

Em 2012, a Secretaria Estadual de Saúde do Estado de Minas Gerais (SESMG) em parceria com o Corpo de Bombeiros do Estado de Minas Gerais (CBMMG) criaram o Suporte Aéreo Avançado de Vida (SAAV) no Estado; trata-se de uma modalidade de Suporte Avançado de Vida (SAV) com a disponibilidade de aeronaves de asa fixa e rotativa, com objetivo de prestação de assistência aeromédica, desde atendimentos primários (resgate), a atendimentos secundários (transportes interhospitalares) e transportes de órgãos e tecidos para transplantes de órgãos além, de apoio à Força Estadual de Saúde em caso de catástrofes no território mineiro (SES, 2012; MINISTÉRIO DA SAÚDE, 2002).

As operações aeromédicas realizadas no território mineiro seguem as legislações oriundas do Comando da Aeronáutica pela Agência Nacional de Aviação

\footnotetext{
Nota de rodapé:

${ }^{1}$,Enfermeira pós graduada em Enfermagem Aeroespacial e Intensivista, atua na $2^{\mathrm{a}}$ Cia do BOA de Minas Gerais; Orcid: https://orcid.org/0000-0002-2712-8106

2 Enfermeira Intensivista e pós graduada em Enfermagem Aeroespacial, atua na $2^{\mathrm{a}}$ Cia do BOA de Minas Gerais.

${ }^{3}$ Médico atuou na $2^{a}$ Cia do BOA de Minas Gerais;

${ }^{4}$ Capitão e piloto no Corpo de Bombeiros de Minas Gerais (CBMMG) na $2^{\mathrm{a}}$ Cia do BOA .
} 
Civil (ANAC) e pelo Ministério da Saúde (ANAC, 2019; MINISTÉRIO DA SAÚDE, 2002).

O acionamento do SAAV ocorre pelas centrais de regulação do Corpo de Bombeiros ou Serviço de Atendimento Móvel de Urgência (SAMU) da região. Após regulação e avaliação ocorre o empenho da aeronave e deslocamento da equipe para o local do atendimento (CAIAFA, 2019). Como experiência exitosa a $2^{\mathrm{a}}$ Cia do Batalhão de Operações Aéreas (BOA) também utiliza mais um mecanismo para acionamento rápido, pelo aplicativo de celular whatsapp com o grupo titulado "Acione Arcanjo", neste consta ao menos um representante de todos os serviços públicos e privados de atendimento ás urgências e emergências do Sul de Minas.

O atendimento e transporte executado por aeronaves é um instrumento favorável para aumento da taxa de sobrevivência de vítimas, uma vez que o tempo resposta entre o atendimento inicial ao tratamento definitivo pode ser minimizado por fatores logísticos envolvendo o trajeto da vítima quando comparado com o terrestre (CARDOSO et. al. 2014). Quando se trata de resgaste em locais de difícil acesso, como em regiões montanhosas, o emprego da aeronave rotativa pode ser indispensável (LI, DONG, 2014).

Haja vista, a expansão das práticas de atividades científicas, de lazer e esportes em ambientes inóspitos e montanhosos e, o aumento de incidentes envolvendo vítimas nestes locais, tornou-se imprescindível a preparação de grupos de resgate especializados, como o SAAV, para prestar assistência (ARAUJO, LUZ, JUNIOR, 2021; NETTO, 2013).

O objetivo deste artigo é relatar a experiência do SAAV na operação de resgate em local montanhoso de difícil acesso no Sul de Minas Gerais conhecido como Serra Fina.

\section{METODOLOGIA}

Trata-se de um relato de experiência vivenciada pelos tripulantes da $2^{\mathrm{a}}$ Cia do BOA situado em Varginha-MG. Para o embasamento teórico que subsidiou a prática e que reverberou na construção deste relato utilizou-se referências bibliográficas do acervo pessoal dos autores e buscas nas seguintes bases on-line: Literatura LatinoAmericana e do Caribe em Ciências da Saúde (LILACS), Biblioteca Eletrônica Cientifica Online (SCIELO), através da combinação entre si dos seguintes 


\section{CON \\ CONGRESSO AEROMÉDICO BRASILEIRO}

descritores: "Resgate Aéreo", "Trabalho de Resgate" e "Gestão de Recursos da Equipe de Assistência à Saúde", das publicações de 2012 a 2021.

\section{RELATO DE EXPERIÊNCIA}

\section{Operação de Resgate na Serra Fina}

A Serra Fina é um complexo montanhoso, localizado na Área de Proteção Ambiental (APA) da Serra da Mantiqueira, entre os estados de Minas Gerais, Rio de Janeiro e São Paulo, com altitudes acima de 2.000m; destaca-se o pico da Pedra da Mina, considerado o quarto mais alto do Brasil. Pelos maiores desníveis topográfico do território e com travessias consideradas mais difíceis do Brasil, a Serra Fina se tornou atrativa para realização de trekking, com elevado grau de dificuldade na qual exige técnicas de montanhismo, com pontos restritos de acesso a água, longas horas de caminhadas e exigência de alto nível de resistência e esforço físico. (PASSA QUATRO, 2021; RESGATE AEROMÉDICO, 2019).

Assim, próximo ao meio dia de 06 de julho de 2019, a equipe da $2^{a}$ Cia do BOA, foi acionada para resgate e atendimento médico a uma vítima, do gênero feminino, com 52 anos, portadora de hipertensão arterial, que apresentou um mal súbito durante a travessia da Serra Fina. A equipe de operadores de suporte médico composto por um médico e uma enfermeira, dois tripulantes operacionais e o piloto tripularam a aeronave modelo Airbus H125, conhecida como esquilo e nomeada como "Arcanjo 03", decolou de Varginha-MG e pousou na Serra Fina ás 12h50min, próximo a região conhecida como Alto do Capim Amarelo. Em uma subida íngreme, com ventos fortes, vegetação alta e baixa temperatura (Figura 1), a equipe, munida com equipamentos nas mochilas, percorreu uma trilha por cerca de 20 minutos até acessar a vítima para início do atendimento.

A assistência médica foi pautada nos protocolos atuais de atendimento préhospitalar como, o Prehospital Trauma Liffer Suport (PHTLS) e Advanced Cardiovascular Life Support (ACLS). A vítima encontrava-se com rebaixamento de nível de consciência, hipotérmica e baixa saturação. No local, foi iniciada oferta de oxigênio suplementar, correção da hipotermia e retirada rápida da vítima do local com a maca modelo SKED, devido quadro clínico e condições climáticas críticas. 


\section{CONAER \\ CONGRESSO AEROMÉDICO BRASILEIRO}

Figura 1- Local do atendimento com aeronave Airbus H145 (Serra Fina, município de Passa Quatro - MG, 2019)
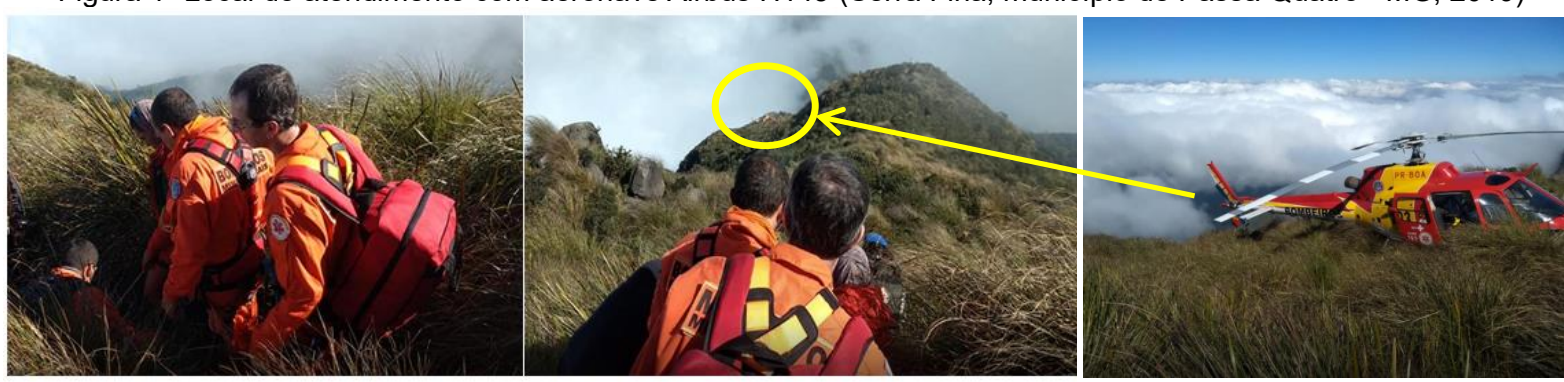

Fonte: Autores.

Optou-se pela retirada da vítima com a maca SKED por ela ser provida de um sistema seguro de fixação, na qual garante a integridade e proteção total à vítima, podendo ser ancorada ao helicóptero verticalmente ou horizontalmente. É ideal para resgates e transporte de vítimas em praticamente qualquer situação. Outro fator que conferiu a adesão da aplicação dessa maca neste atendimento foi sua flexibilidade, que permite que seja enrolada e acondicionada em uma mochila própria para transporte que possibilitou a equipe carregá-la com eficiência até a vítima (CAMARGO, SANTOS, BLASIUS, 2017).

O Arcanjo 03 decolou da Serra Fina e pousou em um campo na cidade de Passo Quatro-MG, onde o médico e enfermeira puderam dar continuidade na assistência á vítima, com instalação de acesso venoso periférico, infusão de solução endovenosa e sedação em sequência rápida seguida de instalação de uma via aérea definida, onde se pôde continuar oferta de oxigênio suplementar. Após estabilização da vítima, procedeu-se com a decolagem da aeronave para a cidade de Varginha-MG, onde a paciente foi encaminhada o Hospital de referência para cuidados intensivos. Após tomografia constatou-se que a vítima apresentou Acidente Vascular Encefálico.

\section{CONSIDERAÇÕES FINAIS}

A atividade de busca e salvamento em montanha deve se amparar aos preceitos de alta excelência (ARAUJO, LUZ, JUNIOR, 2021), contando com equipe especializada, com condições físicas e psicológicas para suportar os fatores estressantes que as missões como essas geram e, dispor de equipamentos e materiais necessários para cumprir a missão com êxito, visando sempre os pressupostos do Crew Resource Management (CRM). 


\section{CONAER \\ CONGRESSO AEROMÉDICO BRASILEIRO}

\section{REFERÊNCIAS}

AGÊNCIA NACIONAL DE AVIAÇÃO CIVIL (ANAC). Regulamento Brasileiro de Aviação Civil N. 90, de 12 de abril de 2019.

ARAUJO, L. I.; LUZ, R. M.; JUNIOR, A. R. I. Planejando uma operação de resgate em montanha. Revista Exército Brasileiro. Disponível em: < http://ebrevistas.eb.mil.br/RCEsSEx/article/view/6935/5986>. 2021. Acesso em 22 de maio de 2021.

CAIAFA, R. Parceria entre SES-MG e Corpo de Bombeiros que salva vidas. SES MG. Disponível em: <http://www.saude.mg.gov.br/component/gmg/story /10946parceria-entre-ses-mg-e-corpo-de-bombeiros-que-salva-vidas>. Acesso em 20 de de maio de 2021.

CAMARGO, J. N.; SANTOS, L. S.; BLASIUS, L. A utilização da técnica de McGuire em resgate de difícil acesso pelo Batalhão de Polícia Militar de Operações Aéreas. Piloto Policial. 2017. Net. Disponível em: < https://www.pilotopolicial.com.br/utilizac ao-da-tecnica-do-mcguire-em-resgate-de-dificil-acesso-pelo-batalhao-de-policiamilitar-de-operacoes-aereas/>. Acesso em 23 de maio de 2021.

CARDOSO, R. G. Resgate aeromédico a traumatizados: experiência na região metropolitana de Campinas, Brasil. Revista do Colégio Brasileiro de Cirurgia, v. 4, n. 4, p.236-244, 2014.

LI, Y.; DONG, X. Mountain Disaster Incidents and Corresponding Emergency Rescue Measures. Procedia Engineering, v. 71, p. 207-2013, 2014.

MINISTÉRIO DA SAÚDE. Portaria N. 2.048, de 5 de novembro de 2002.

NETTO, S. O. Resgates em áreas remotas - responsabilidades perante a lei. Disponível em: https://jus.com. br/artigos/25813/resgates-em-areas-remotasresponsabilidades-perante-a-lei. 2013. Acesso em: 20 de maio de 2021.

PASSA QUATRO, PREFEITURA MUNICIPAL DE. Passa Quatro Turismo e Meio Ambiente. Net. Disponível em: <https://www.passaquatro.mg.gov.br/turismo>.Acesso em: 20 de maio de 2021.

RESGATE AEROMEDICO. Equipes do corpo de bombeiros e do SAMU realizam difícil resgate a 6.800 pés na trilha da Serra Fina-MG. Net. Disponível em: 


\section{CONAER \\ CONGRESSO AEROMÉDICO BRASILEIRO}

<https://www.resgateaeromedico.com.br/equipes-do-corpo-de-bombeiros-e-dosamu-realizam-dificil-resgate-a-6-800-pes-na-trilha-da-serra-fina-mg/>. Acesso em 23 de maio de 2021.

SECRETARIA ESTADUAL DE SAÚDE DO ESTADO DE MINAS GERAIS (SES-MG). Extrato do Termo de Cooperação Técnica $n^{\circ}$ 1964/2012. Diário do Executivo, Caderno 1, 2012.

\section{AGRADECIMENTOS}

- Aos colegas da $2^{\mathrm{a}}$ Cia de Operações Aéreas de Varginha-MG;

- Aos Comandantes das Cia de Operações Aéreas: Mj Fábio Alves Dias e Mj Nelson Santana Camargo;

- Aos colegas, em especial, que atuaram na missão descrita neste trabalho, a saber: Piloto Capitão João Bosco Lara Júnior, 2a Sgt. Deusdet Moreira de Souza, $2^{\circ}$ Sgt. Thiago de Oliveira Cruz Bueno; Dr. Márcio Antônio Rios e Enfermeira Camila Mendes dos Santos.

- A enfermeira Simone A. R. S. Junqueira pela participação no desenvolvimento deste estudo;

- Ao CISSUL/SAMU. 